\section{Growth and Flowering of Lantana camara L. subsp. camara as Affected by Triapenthenol and Environmental Factors}

Aristidis S. Matsoukis ${ }^{1}$ and Aikaterini G. Chronopoulou-Sereli ${ }^{2}$

Department of General Sciences, Agricultural University of Athens, Iera odos 75-Athens 11855, Greece

\author{
John K. Chronopoulos ${ }^{2}$ \\ Department of Crop Science, Agricultural University of Athens, Iera odos \\ 75-Athens 11855, Greece
}

Additional index words. growth regulator, lantana, light intensity

\begin{abstract}
The various concentration effects of the growth regulator triapenthenol $(0$, 43.75, 87.5, 175, and $350 \mathrm{mg} / \mathrm{pot}$ ) on the growth and flowering of Lantana camara $\mathrm{L}$. subsp. camara under different shading levels $(0 \%, 28 \%$, and $66 \%)$ were studied in 1997 and 1998 in a glasshouse in Attica, Greece. It was found that minimum temperature and photosynthetic photon flux density were the most important factors to plant growth. The growth index (GI) decreased as the regulator concentration increased while the number of flower heads per plant increased up to a maximum at the concentration of $87.5 \mathrm{mg}$ triapenthenol per pot with a decrease afterwards, at all shading levels. The interaction between shading level and triapenthenol concentration significantly affected GI and flowering of lantana plants. The growth index of the control plants increased and the number of flower heads per plant decreased significantly at all concentration levels examined, as shading increased from $0 \%$ to $66 \%$. Triapenthenol resulted in darker green foliage and at higher concentrations in some leaf distortion. The most attractive plants were produced with triapenthenol concentration of $87.5 \mathrm{mg} / \mathrm{pot}$ at the nonshaded plot; they were small with the greatest number of flowers. Chemical name used: $(E)-(R S)-1-c y c l o h e x y l-4,4-$ dimethyl-2-(1H-1,2,4-triazol-1-yl)-pent-1-en-3-ol (triapenthenol).
\end{abstract}

Lantana camara L., a vigorous small shrub (Ruter, 1996), has ornamental interest because of its dense attractive foliage and the multi-coloured flowers (Pizzetti and Cocker, 1975). Due to these features, lantana and especially Lantana camara L. subsp. camara is used widely in several countries as landscape plant. The use of plant growth regulators is required to produce marketable plants.

Triapenthenol, a growth regulator of the triazole class (Graebe, 1987), has been shown to provide height control at Pelargonium hortorum 'Yours Truly' (Tayama and Carver, 1990) and Fuchsia sp. (Biermann, 1989), compactness of Exacum affine cv. Blue Champion (Barrett et al., 1987); and control of the internode length of many ornamental plants (Lürssen and Reiser, 1987). It was also found that, in general, triapenthenol increases flowering (Lürssen, 1988).

The uptake and translocation of growth regulators is known to be influenced by temperature and light intensity (Muzik, 1976). A change in light intensity by the use of shading

Received for publication 13 Aug. 2001. Accepted for publication 21 May 2002. This work has been partly funded by the State Scholarships Foundation of Greece. The first author thanks Pr. Charles Stirton (Director of the National Botanic Garden of Wales, U.K.) for the identification of the experimental plants.

${ }^{1}$ Research Agronomist.

${ }^{2}$ Professor.

HortScience, Vol. 38(2), April 2003
Triapenthenol (Baronet 70\% w/w, Bayer, Germany) was applied once as foliar spray solution $(0.25 \mathrm{~L} /$ plant $)$, to runoff, on plants of lantana at the concentrations of $0,175,350$, 700 , and $1400 \mathrm{mg} \cdot \mathrm{L}^{-1}(0,43.75,87.5,175$, and $350 \mathrm{mg}$ /pot a.i., respectively). A surfactant [Agral 90, 94.8\% (w/w) nonylphenolethoxylate Zeneca, United States] was used at $0.25 \mathrm{~mL} \cdot \mathrm{L}^{-1}$

The experiment was carried out according to the two-factor completely randomized design. The first factor had three shading levels created using shading polyethylene nets; one black thin and one dense woven (models 103 and 201 respectively of Manioudaki Bros S. A. knitting factory Greece) were placed the first at the $\mathrm{R}_{2}$ and the second at the $\mathrm{R}_{3}$ shade plot while a nonshaded plot $\left(\mathrm{R}_{1}\right)$ was also existed. The second factor had five levels corresponding to the triapenthenol concentrations. There were eight one-plant replicates.

Environmental data including temperature and relative humidity $(\mathrm{RH})$ were monitored by three dataloggers 903 (Wilh. Lambrecht $\mathrm{GmbH}$, Germany) with sensors for these parameters (model 809 L 0-100 of Wilh. Lambrecht $\mathrm{GmbH}$, Germany; accuracy \pm 0.3 ${ }^{\circ} \mathrm{C}$ at $0{ }^{\circ} \mathrm{C}$ and $\pm 2.5 \%$ for temperature and $\mathrm{RH}$ respectively). Mean daily maximum and minimum temperatures ranged from 27.2 to 33.0 and 17.1 to $18.1^{\circ} \mathrm{C}$, respectively, with their higher values at the nonshaded plot $\left(\mathrm{R}_{1}\right)$ and the second experimental period (1998) being warmer than the first (1997). On the contrary, the mean daily RH was lower at 1998 at all plots without differing more than $5.3 \%$ among them. Photosynthetic photon flux density $(P P F)$ measurements were taken hourly during daytime, from 0500 to $1600 \mathrm{HR}$ Greenwich meridian time beneath the shading materials, at the top of the plant canopies, using three LI-190 SA quantum sensors (LI-COR, Lincoln, Nebr.; sensitivity of $8 \mu \mathrm{A}$ per 1000 $\mu \mathrm{mol} \cdot \mathrm{m}^{-2} \cdot \mathrm{s}^{-1}$ ) each connected with a LI-1000 datalogger (LI-COR). During the experimental periods, $P P F$ ranged from 390 to 1340 $\mu \mathrm{mol} \cdot \mathrm{m}^{-2} \cdot \mathrm{s}^{-1}$ for the nonshaded plot, while for the shaded plots $\mathrm{R}_{2}$ and $\mathrm{R}_{3}$ it ranged from 280 to 970 and 140 to $470 \mu \mathrm{mol} \cdot \mathrm{m}^{-2} \cdot \mathrm{s}^{-1}$, respectively. The higher mean values of $P P F$ were recorded during 1998 and presented greater reduction with the increase of shading than the other environmental parameters.

Biometric measurements were carried out every 5 d until 18 and 23 Nov. 1997 and 1998, respectively, and included plant height (at the level of the tallest shoot from pot rim), maximum plant diameter (width 1 ), perpendicular width to maximum diameter (width 2 ) and the number of flower heads per plant (with three at least open florets). Growth index (GI) was calculated as (height + width $1+$ width 2$) / 3$ according to Ruter (1996). To study the change of the GI after pinching (as computed by subtracting initial from final GI) and the total number of flower heads per plant, statistical models were used (Dimopoulos, 1997) and also analysis of variance (after the exclusion for each treatment of the two extreme values) with mean separation by Tukey's honestly significant difference (HSD) test. The combined effects of temperature, 


\section{Crop Production}

relative humidity and $P P F$ on plant GI change were evaluated by a step-wise multiple regression analysis technique in each treatment. The statistical analysis was conducted separately for each year of the experiments because the measured plant characteristics appeared statistically significant variation among 1997 and 1998, for a number of same treatments, probably due to the different environmental conditions between the 2 years.

\section{Results and Discussion}

During the second experimental period the plants presented greater increases to their GI changes and number of flower heads at all plots due to the more advantageous environmental conditions referred to higher values of $P P F$ and temperature.

Significant differences to the changes of the GI and the total number of flower heads per plant among the various triapenthenol concentrations and shading levels were identified (Table 1). Concentration $\times$ shading level interaction was significant for both cases.

Treated plants with triapenthenol had smaller changes of GI (Figs. 1a and 2a) than the nontreated ones; this reduction may be attributed to the lower content of their biologically active gibberellic acids induced by triapenthenol application (Rademacher, 1991) compared to nontreated plants. According to

Table 1. Analysis of variance for effects of shading level and concentration of triapenthenol on the growth index change (GI) and the number of flowerheads/ lantana plant for the years 1997 and 1998.

\begin{tabular}{|c|c|c|c|c|c|}
\hline \multirow[b]{2}{*}{ Source } & \multirow[b]{2}{*}{$\mathrm{df}$} & \multicolumn{2}{|c|}{ GI (cm) } & \multicolumn{2}{|c|}{ No. of flowerheads } \\
\hline & & 1997 & 1998 & 1997 & 1998 \\
\hline & & \multicolumn{4}{|c|}{ (- } \\
\hline $\mathrm{S}^{\mathrm{z}}$ & 2 & $84.75^{* * *}$ & $123.43^{* * *}$ & $4941.70^{* * * *}$ & $5066.10^{* * * *}$ \\
\hline $\mathrm{CT}^{\mathrm{y}}$ & 4 & $1370.27^{* * *}$ & $1709.84^{* * *}$ & $4538.56^{* * *}$ & $4043.46^{* * *}$ \\
\hline $\mathrm{S} \times \mathrm{CT}$ & 8 & $41.87^{* * *}$ & $63.43^{* * *}$ & $101.51^{* * *}$ & $135.46^{* * *}$ \\
\hline Error & 75 & 0.90 & 0.82 & 5.34 & 6.44 \\
\hline
\end{tabular}

${ }^{2} \mathrm{~S}=$ Shading level.

${ }^{\mathrm{y}} \mathrm{CT}=$ Concentration of triapenthenol.

${ }^{* * *}$ Significant at $P=0.001$.

Lürssen and Reiser (1987) triapenthenol inhibited gibberellin biosynthesis in vitro between ent-kaurene and ent-kaurenoic acid and may be interfered with both gibberellin and sterol metabolism in plants. Higher triapenthenol concentrations produced smaller plants at all shading levels.

However, the number of flower heads increased with increasing concentrations of triapenthenol up to $87.5 \mathrm{mg} / \mathrm{pot}$, followed by a decrease at higher concentrations (Figs. $1 \mathrm{~b}$ and $2 \mathrm{~b}$ ), indicating that a saturation point existed above which flowering was decreased. The regulator-treated plants produced more flowers than the nontreated ones which comes to conflict for gardenia treated with triapenthenol at 70,140 , and $280 \mathrm{mg} \cdot \mathrm{L}^{-1}$ (ChronopoulouSereli et al., 1998).
Increasing shading from $0 \%\left(\mathrm{R}_{1}\right)$ to $28 \%$ $\left(R_{2}\right)$ reaching $66 \%$ at $R_{3}$ plot caused generally no significant changes of GI for plants treated with the same concentration of the regulator. On the other hand, the GI of the nontreated plants was increased significantly (Tukey's HSD test); this could be attributed to plants effort to avoid low light environments, a known feature of shade intolerant plants (Tang, 1997). An inverse relation between light intensity and plant growth parameters was also reported by Sim et al. (1997) on Campanula takesimana, Norcini et al. (1991) on Photinia fraseri and Svenson (1993) on Acalypha hispaniolae plants.

The number of flower heads was significantly decreased for the plants treated with the same concentration of the regulator while

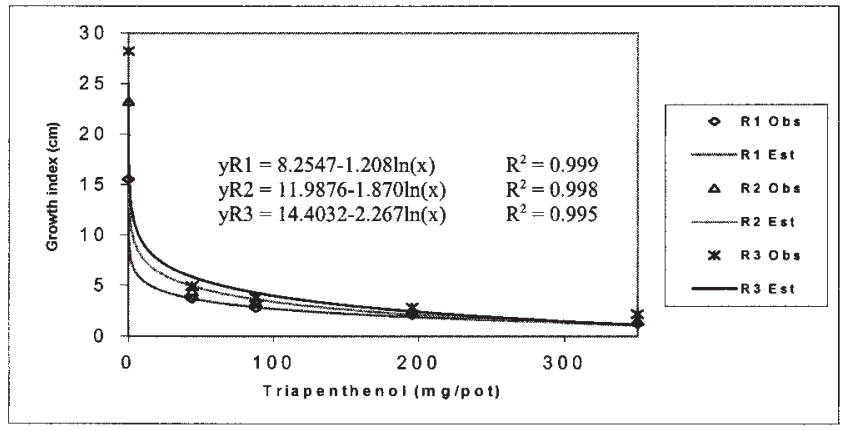

b

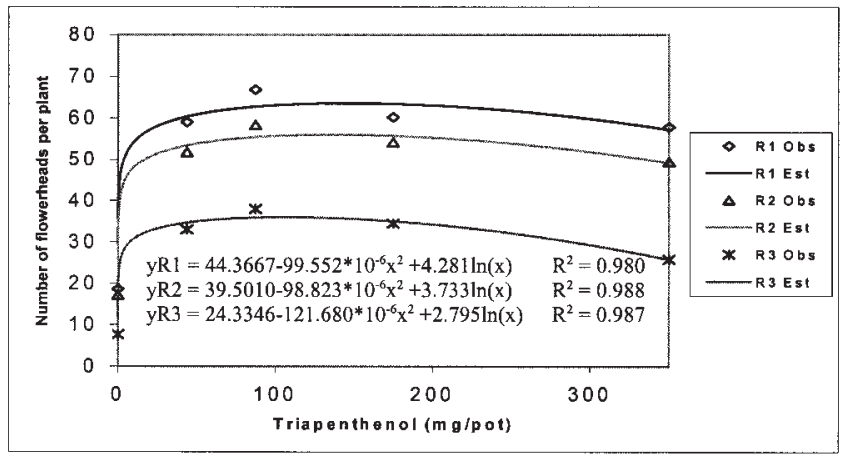

Fig. 1. Changes of growth index (GI) and number of flowerheads/lantana plant as a function of triapenthenol concentrations $(0,43.75,87.5,175$, and 350 $\mathrm{mg} /$ pot), at the plots $\mathrm{R}_{1}, \mathrm{R}_{2}$, and $\mathrm{R}_{3}$. Growth index $=$ (height of tallest shoot + maximum diameter + perpendicular to maximum diameter) $/ 3$. Each value is the mean of six replicates. R1obs, R2obs, R3obs, and R1est, R2est, R3est are the measured and estimated GI (a) and flower (b) values, respectively for 1997.

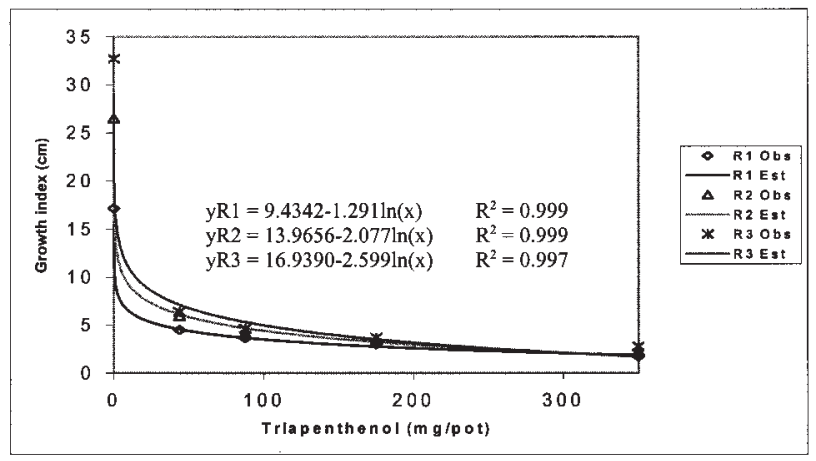

b

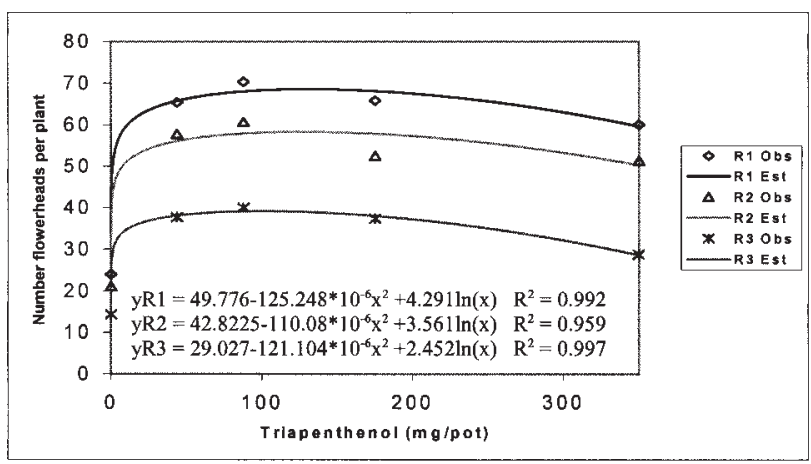

Fig. 2. Changes of growth index (GI) and number of flowerheads/lantana plant as a function of triapenthenol concentrations $(0,43.75,87.5,175$, and 350 $\mathrm{mg} / \mathrm{pot}$ ), at the plots $\mathrm{R}_{1}, \mathrm{R}_{2}$, and $\mathrm{R}_{3}$. Growth index $=$ (height of tallest shoot + maximum diameter + perpendicular to maximum diameter)/3. Each value is the mean of six replicates. R1obs, R2obs, R3obs, and R1est, R2est, R3est are the measured and estimated GI (a) and flower (b) values, respectively for 1998 . 
for the nontreated ones significant differences were found only between $0 \%$ and $66 \%$ as well as $28 \%$ and $66 \%$ shading (Tukey's HSD test). The great reduction of flowering at $R_{3}$ plot could be attributed to the strong light exclusion (Muzik, 1976).

The multiple regression analysis showed that minimum temperature and $P P F$ were the most important factors in plant GI change for 1997 and 1998 respectively (data not shown), at all shading levels. Kamoutsis et al. (1998) reported that the maximum temperature was the most important factor in the development of gardenia.

Plants treated with triapenthenol exhibited darker green foliage than the nontreated ones consistent with previous studies (Lürssen and Reiser, 1987). Some leaf distortion was noticed in plants treated with the higher concentrations of the regulator. Kamoutsis et al. (1998) observed wrinkling on the leaves of Gardenia jasminoides treated with triapenthenol.

It is also interesting to note, that the more attractive plants were produced with triapenthenol at the concentration of $87.5 \mathrm{mg} / \mathrm{pot}$ at the nonshaded plot; they were small with the greatest number of flower heads, over three times the respective number of the nontreated ones at the same plot.

\section{Literature Cited}

Barrett, J.E., M.E. Peacock, and T.A. Nell. 1987. Height control of exacum and chrysanthemum with paclobutrazol, XE-1019, flurprimidol and RSW-411. Proc. Fla. State Hort. Soc. 99: 254-256.

Biermann,W. 1989. Chemische Wachstumsregulierung bei Fuchsien. Nicht alles was hemmt ist auch sinnvoll. Gb + Gw, Gärtnerbörse und Gartenwelt 89(35):1708-1710.

Chronopoulou-Sereli, A., A. Kamoutsis, and J. Chronopoulos 1998. Wirkung von paclobutrazol und triapenthenol bei Gardenia jasminoides in zusammenhang mit temperatur und sonnenstrahlung. Gartenbauwissenschaft 63(5):228-232.

Dimopoulos, I. 1997. La mise en œuvre des modèles statistiques linéaires et non linéaires en sciences de l'environnement. Doctorat, Thèse de l'Université Paul Sabatier-Toulouse III, France.

Graebe, J.E. 1987. Gibberellin biosynthesis and control. Annu. Rev. Plant Physiol. 38:419-465.

Kamoutsis, A., A. Chronopoulou-Sereli, and C. Holevas 1998. Interaction of triapenthenol and environmental factors on the growth and flower bud formation of Gardenia jasminoides Ellis. Can. J. Plant Sci. 78:635-640.

Lürssen, K. and W. Reiser 1987. Triapenthenol-A new plant growth regulator. Pestic. Sci. 19: 153-164.

Lürssen, K. 1988. Plant physiological and biochemical activity of the new plant growth regulator triapenthenol (RSW 0411). Pflanzenschutz-
Nachrichten Bayer 41:306-339.

Muzik, T.G. 1976. Influence of environmental factors on toxicity to plants. p. 203-247. In: L.J. Audus (ed.). Herbicides. Vol. II. Academic, London.

Norcini, J.G., P.C. Andersen, and G.W. Knox 1991. Light intensity influences leaf physiology and plant growth characteristics of Photinia $\times$ fraseri. J. Amer. Soc. Hort. Sci. 116:1046-1051.

Pizzetti, I. and H. Cocker 1975. Lantana, p. 720-723. In: J.L. Hochmann (ed.). Flowers, a guide for your garden. Volume II. Harry N. Abrams, New York.

Rademacher, W. 1991. Biochemical effects of plant growth retardants, p. 169-200. In: H.W. Gausman (ed.). Plant biochemical regulators. Marcel Dekker, New York.

Ruter, J.M. 1996. Paclobutrazol application method influences growth and flowering of 'New Gold' lantana. HortTechnology 6:19-20.

Sim, Y., Y. Han, J. Woo, Y. Seong, K. Choi, and B. Choi 1997. Effect of shading and growth regulator on growth and flowering of potted Campanula takesimana Nakai. RDA J. Hort. Sci. 39(1):89-94.

Svenson, E.S. 1993. Shading and pot color influence growth and flowering of strawberry firetails. Proc. Fla. State Hort. Soc. 106:286-288.

Tang, Y. 1997. Light. p. 3-40. In: M.N.V. Prasad (ed.). Plant ecophysiology. Wiley, New York.

Tayama, H.K. and S.A. Carver 1990.Zonal geranium growth and flowering responses to six growth regulators. HortScience 25:82-83. 